\title{
A SOBERANIA BRASILEIRA SOBRE O PRÉ-SAL: A UTILIZAÇ̃̃O PLENA DOS RECURSOS ORIUNDOS DA AMAZÔNIA AZUL E SUA LOGÍSTICA
}

\author{
Cássio Hatsumi Matsumoto ${ }^{1}$ \\ Messias Bezerra da Silva Neto 2 \\ Rui Barbosa de Lima Neto ${ }^{3}$ \\ Helena Lucia Damasceno Ferreira ${ }^{4}$
}

\section{RESUMO}

Este artigo analisa o pré-sal, considerado a partir da grande reserva de hidrocarbonetos localizada dentro da área conhecida como "Amazônia Azul", constitui uma fonte de riqueza essencial para o desenvolvimento brasileiro, dessa forma, deve ser explorado de maneira eficiente. Para que isso ocorra um fator essencial é uma logística eficiente para o transporte de pessoal, de material, e de produtos extraídos. A exploração plena desse recurso só poderá ser feita com a garantia da soberania nacional sobre tais recursos.

Palavras-chave: Pré-sal, Amazônia Azul, Brasil, soberania, logística, exploração.

\section{ABSTRACT}

This article analyzes the pre-salt, considered from the great reservoir of hydrocarbons located within the area known as "Blue Amazon" area, is a key source of wealth for the Brazilian development thus should be explored efficiently. For this to happen one factor is crucial: efficient logistics for the transportation of personnel, materials and extracted goods. Full exploitation of this feature can only be done with the guarantee of national sovereignty over those resources.

Key-words: pre-salt, blue amazon, Brazil, sovereignty, logistic, exploration.

\section{INTRODUÇÃO}

Recentemente descobriu-se nas águas brasileiras uma nova riqueza para a nação. As reservas de petróleo no pré-sal vêm sendo sondadas desde 2005, mas o anúncio oficial só foi feito no ano de 2007. Essa descoberta é fundamental para o Brasil, um Estado que vem ascendendo constantemente em importância no cenário mundial. Através do aumento das reservas de petróleo, o país aumenta seu poder político e econômico, passando da condição de autossuficiente para a condição de exportador da principal matéria-prima para a geração de energia na atual matriz energética mundial.

\footnotetext{
${ }^{1}$ Aluno da Escola de Formação de Oficiais da Marinha Mercante/ Bacharelado em Ciências Náuticas, Centro de Instrução Almirante Braz de Aguiar (CIABA), Belém - Pará. E mail: cassiohtmt@gmail.com

${ }^{2}$ Aluno da Escola de Formação de Oficiais da Marinha Mercante/ Bacharelado em Ciências Náuticas, Centro de Instrução Almirante Braz de Aguiar (CIABA), Belém - Pará. E mail: messiasbezerra @ hotmail.com

${ }^{3}$ Aluno da Escola de Formação de Oficiais da Marinha Mercante/ Bacharelado em Ciências Náuticas, Centro de Instrução Almirante Braz de Aguiar (CIABA), Belém - Pará. E mail: rui_nt@ hotmail.com

${ }^{4}$ Professora do Centro de Instrução Almirante Braz de Aguiar. Economista, Mestre em Desenvolvimento e Meio Ambiente Urbano (Universidade da Amazônia); Doutoranda em Ciências Ambientais (UFPA/Embrapa/Museu Paraense Emilio Goeldi). E mail: helenaluciaferreira@yahoo.com.br.
} 
A Petrobrás, empresa brasileira responsável pela extração do petróleo, pioneira na exploração de águas ultraprofundas, elaborou a construção de conhecimentos logísticos e operacionais para o uso do pré-sal, a qual será feita a partir de uma comparação com o modelo clássico do offshore feito principalmente através do modal marítimo com embarcações de apoio logístico.

Entretanto, devido às grandes dimensões (extensão, profundidade e distância da costa), não se sabe até onde é possível realizar adaptações e onde deverão ser aplicadas técnicas inovadoras. Além disso, o principal desafio do pré-sal (além dos desafios físicos) é a redução dos custos de operação, para que o barril possa ser extraído de modo a manter seu preço competitivo em nível mundial (valores futuros em torno de 40 dólares ${ }^{5}$ ).

As novidades do conhecimento estão relacionadas à aplicação de novos tipos de embarcações e aeronaves para transporte de pessoal e de materiais necessários para instalação das plataformas; ao uso de plataformas HUB's, ilhas artificiais longe da costa (que concentrarão todos os recursos necessários às plataformas extratoras) de onde estarão prontas para chegar ao local de uso, percorrendo uma distância relativamente pequena, economizando tempo e aumentando a eficiência logística; a colocação de dutos que terão capacidade de transportar o óleo extraído e a perfuração dos poços de petróleo, os quais terão que superar a camada de sal (com comportamento viscoso devido à profundidade, temperatura e pressão), numa indústria que está acostumada a perfurar rochas. Nesse sentido, este trabalho tem como proposta discussão desses elementos, considerados como essenciais para alavancar o desenvolvimento do setor no país.

O pré-sal representa, dentro da jurisdição brasileira, a riqueza que poderá impulsionar o país para um futuro brilhante. A exploração desse recurso constitui-se como um grande desafio, que deverá ser feito em ação conjunta das esferas pública e privada, através das figuras do Estado, regulamentando as reservas e seu uso, e protegendo nossas riquezas; da comunidade cientifica, que apresentará as melhores soluções para a extração, manutenção e transporte do ouro negro; e das empresas privadas, públicas ou mistas, que serão o baluarte das realizações operacionais.

\section{AMAZÔNIA AZUL E O PRÉ-SAL}

Com o desenvolvimento tecnológico, foi possível a descoberta nas águas, no solo, e no subsolo marinho recursos naturais de importância ímpar para humanidade. Não é à toa, pois, que o mar é objeto da cobiça e do imaginário popular. O interesse brasileiro pelo mar é histórico e amplo, justificável ao passo que apresenta um litoral com aproximadamente 8,5 mil quilômetros de extensão e uma área marítima sobre a qual o Brasil tem jurisdição de extensão aproximada de 4,5 milhões de quilômetros quadrados. Pelo mar o Brasil foi colonizado, foi invadido, foi por onde consolidou sua independência, por onde se estabeleceu e estabelece maior parte de seu comércio e é por onde a soberania nacional é defendida.

O Brasil tem como uma de suas principais características a riqueza de recursos naturais. Esta ocorrência não é exclusividade de seus trechos terrestres, cujo limite, foi estabelecido na gestão de José Maria da Silva Paranhos Junior, o Barão do Rio Branco, quando Ministro das Relações Exteriores; mas também de sua extensão marinha, a Amazônia Azul. Este termo foi cunhado pela primeira vez pelo Almirante Roberto Guimarães, devido à semelhança de riquezas e de área com a floresta Amazônica.

Em consonância com a Convenção das Nações Unidas sobre os Direitos do Mar (CNDUM), que entrou em vigor no ano de 1994, a Amazônia Azul é composta por doze milhas de Mar Territorial (contadas a partir da linha da costa) sobre o qual o Estado exerce "soberania plena em relação às águas, solo, subsolo e espaço aéreo sobrejacente"; doze milhas

\footnotetext{
${ }^{5}$ Fonte: Ministério de Minas e Energia, nov/2009
} 
de Zona Contígua, que se superpõe à Zona Econômica Exclusiva, por uma extensão de 188 milhas (a partir do limite do Mar Territorial), onde o Estado não mais exerce soberania plena, mas tem jurisdição e exclusividade para fins de exploração e aproveitamento, conservação e gestão dos recursos naturais vivos e não-vivos das águas, do solo e do subsolo marinhos, para exploração e aproveitamento econômico e jurisdição, no que se refere à instalação $e$ utilização de ilhas artificiais, instalações e estruturas (plataformas de petróleo, por exemplo), investigação científica marinha e proteção e preservação do meio marinho. Além das áreas supracitadas, o Brasil, numa ação conjunta da Marinha do Brasil, da Petrobrás e da comunidade científica, realiza um projeto conhecido como LEPLAC (Levantamento da Plataforma Continental), que constitui um estudo dirigido sobre os recursos disponíveis nesta área a fim de poder requisitar junto à Comissão de Levantamento da Plataforma Continental (CLPC) da ONU a extensão do limite exterior para além das duzentas milhas marítimas, em consonância com a parte VI da CNDUM.

Dentro dos limites da Amazônia Azul, a Petrobrás descobriu a existência de grandes reservas de petróleo em camadas com profundidades que ultrapassam sete mil metros de profundidade a partir da superfície oceânica. Essa camada, chamada pré-sal, é uma formação geológica irregular - cuja espessura varia de oitocentos a dois mil metros - e que surgiu há mais de 120 milhões de anos, devido à quebra do supercontinente Gondwana, e consequente separação da África da América do Sul.

As grandes reservas de petróleo surgiram devido à deposição de grande quantidade de matéria orgânica sob a camada de sal, depositada em eras mais recentes, e as lâminas mais superficiais da crosta oceânica, que atuam com grande pressão sobre a matéria orgânica, originando o petróleo. Essas reservas estão depositadas, portanto, abaixo da camada de sal, sendo mais profundas dos que as exploradas comercialmente até então, as quais existem no pós-sal e são originarias de vazamentos da camada pré-sal para as superiores.

Estima-se que o pré-sal brasileiro estenda-se de Santa Catarina ao Espírito Santo, numa distância superior a $300 \mathrm{~km}$ da linha litorânea ${ }^{6}$, com área de $149 \mathrm{mil} \mathrm{km}^{2}$. O primeiro campo descoberto, o de Tupi (rebatizado Lula após sua declaração de comercialidade), localizado na Bacia de Santos, tem potencial para elevar as reservas da Petrobras em até $60 \%{ }^{7}$. As reservas do pré-sal, estimadas em 1,6 trilhões de metros cúbicos de petróleo e gás, podem colocar o Brasil como o sexto maior produtor de petróleo no mundo, atrás somente de Arábia Saudita, Irã, Iraque, Kuwait e Emirados Árabes.

As descobertas das grandes reservas de petróleo no litoral brasileiro geraram outras preocupações ao Estado, no que concerne à defesa do patrimônio nacional. A área relativa ao pré-sal estende-se para além dos limites da Amazônia Azul, em águas internacionais, onde qualquer nação, com autorização da Autoridade Internacional dos Fundos Marinhos, com sede na Jamaica, poderia realizar exploração dos recursos da coluna d'água, do solo e subsolo marinho. Além disso, a soberania da própria Amazônia Azul está ameaçada por agentes externos devido à extensão de suas reservas, sua importância política (dada a crescente necessidade mundial de energia gerada através do petróleo) e econômica.

As descobertas do pré-sal colocam o Brasil como um "player" de importância no cenário mundial, por esta razão, com objetivo de garantir a soberania nacional sobre nossas riquezas (e sua importância política e econômica), o Estado incluiu as reservas petrolíferas marítimas como uma de suas prioridades no Plano de Defesa Nacional. Desta forma, o Estado procura manter a segurança, "condição que permite ao País a preservação da soberania e da integridade territorial, a realização dos seus interesses nacionais, livre de pressões e ameaças de qualquer natureza, e a garantia aos cidadãos do exercício dos direitos e deveres constitucionais", através de um conjunto de medidas com expressão militar, visando manter a soberania nacional na existência de ameaças externas declaradas, eminentes ou potenciais.

\footnotetext{
${ }^{6}$ FONTE: Petrobras, 2011

${ }^{7}$ FONTE: Revista Veja, 2011
} 
Desta maneira, procura-se proteger a área marítima, responsável por $90 \%^{8}$ da extração de petróleo nacional, através do reforço da Marinha Brasileira, principal órgão atuante nos nossos mares.

\section{LOGÍSTICA: O GRANDE DESAFIO DO PRÉ-SAL}

O processo de globalização não é recente, a cunhagem do termo sim, todavia é um processo que foi iniciado com a produção do excedente a partir do domínio da agricultura pelo homem e o consequente aparecimento do comércio. Por meio de transações comerciais, iniciou-se o processo de assimilação e mistura de culturas distintas. Foi durante a época do mercantilismo que esse movimento se intensificou. As Grandes Navegações desbravando mares nunca dantes navegados, realizando longas viagens em busca de especiarias e preciosidades, recursos naturais e minerais. O comércio tem uma variável importante: o transporte. Do qual extrairemos um termo contemporâneo mais abrangente: a logística. Cada país precisa usar seus recursos de forma mais eficiente, buscando se especializar em atividades apropriadas à dotação de fatores e obtenção de sensíveis economias de escala em sua produção.. É nesse contexto que inserimos todo potencial petrolífero brasileiro.

Como visto, a exploração do pré-sal impõe uma série de desafios à prospecção offshore, dentre várias está a distância da costa, por exemplo. Isso remete a uma importante constatação: o transporte é das tarefas logísticas a mais primordial, pois é ele que agrega o valor de lugar ao produto, seu conceito se confundindo, muitas vezes, com a própria definição de logística, devendo-se isso a sua parcela de participação nos custos totais logísticos. Para Christopher (2007), parafraseando, a logística é definida como o processo de gerenciar estrategicamente a aquisição, movimentação e armazenagem de materiais, peças e produtos acabados (e os fluxos de informações correlatas), através de organização de seus canais de marketing, de modo a maximizar a lucratividade presente e futura, através do atendimento dos pedidos a baixo custo. O petróleo proveniente das plataformas precisando ser transportado para as refinarias, através de navios ou dutos, deve grande parte de seu custo operacional de produção a esse transporte, portanto a diminuição do mesmo é bastante relevante e a logística é, nesse contexto, a ciência que visa à adaptação dos meios disponíveis e das formas estratégicas para alcançar os propósitos das organizações comerciais.

O transporte marítimo é o modal mais utilizado no comércio internacional. Apresenta vantagens como: maior capacidade de carga, carrega qualquer tipo de carga e menor custo de transporte; e como desvantagens: necessita de transbordo nos portos, distância dos centros de produção, maior exigência de embalagens, menor flexibilidade nos serviços aliados e frequentes congestionamentos nos portos. $\mathrm{O}$ transporte dutoviário também se mostra como opção para o escoamento de mercadorias, apresentando como vantagens o volume de tráfego, não apresentam restrição de funcionamento ( 24 horas por dia, 7 dias na semana), não existe veículo vazio a retornar; e desvantagens o alto custo da construção, necessita de grande área a ser desapropriada, não são flexíveis e limitados quanto a carga que podem transportar. Em termos gerais, a consonância das variáveis custo e lucro está vinculada à harmonização do que se denomina como transporte intermodal e/ou multimodal.

Determinar onde, como, quanto e quando produzir são questões a serem respondidas para o melhor planejamento. Considera-se que com a capacidade de produção limitada e geograficamente dispersa, fornecer mercadorias certas no instante e no local (just in time) necessários para manufatura é crítico, e, portanto, a programação do fluxo de materiais é uma das principais decisões neste nível de planejamento (BALLOU, 2006).

Desde a descoberta do pré-sal, a logística relacionada à instalação e manutenção das plataformas extratoras, e ao transporte do produto extraído para as refinarias, se apresentou como um grande desafio. A exploração em águas profundas, muito profundas e ultra

\footnotetext{
${ }^{8}$ FONTE: Agência Nacional de Petróleo, Gás e Biocombustíveis.
} 
profundas é especialidade da Petrobras, que vem quebrando recordes de profundidade constantemente. Em uma ação conjunta da comunidade científica e da Petrobras desenvolveram-se diversas tecnologias para que o pré-sal pudesse ocorrer efetivamente.

O principal desafio logístico apresentado pelo pré-sal é o transporte de pessoal. No offshore, este é feito exclusivamente por helicópteros. Só na Bacia de Santos, transporta-se por dia cerca de 300 pessoas $^{9}$. Apesar da agilidade da operação, implantar este sistema para exploração do pré-sal resulta em um aumento significativo de custos. Desta forma, uma solução alternativa deve ser adotada, não somente para a redução de custos, mas também para diminuir a dependência do modal aéreo.

Inicialmente, o transporte para as plataformas operando no pré-sal foi feito segundo o modelo adotado pelo offshore, entretanto, o uso exclusivo de helicópteros exige a redução da capacidade de transporte para dois terços ${ }^{6}$ do total, com o intuito de carregar mais combustível, necessário para atravessar distâncias, duas ou três vezes maior do que aquelas praticadas no offshore.

Num cenário futuro, a demanda será de aproximadamente 1100 pessoas por dia, desta forma, torna-se-há inviável a adoção desse modelo, agora clássico. A instalação de uma base intermediária (entre a costa e as plataformas) conhecida como HUB - capaz de acomodar até 400 pessoas e dotada de toda infraestrutura para operação com helicópteros e emergências médicas - permitirá a redução dos custos. O transporte "em massa" de pessoal oriundo da terra será feito por embarcações de alta velocidade (EAV) até o HUB, onde haverá trasbordo da tripulação. A partir do HUB, o transporte será feito por helicópteros, em distâncias extremamente reduzidas, de modo que o transporte aéreo, de alta velocidade, utilizará sua capacidade total, aumentando sua eficiência logística.

Os desafios neste tipo de operação estão relacionados ao conforto daqueles embarcados na EAV's, que deverão operar a quarenta nós, com balanço reduzido e ao transbordo EAV - HUB, que exigirá a adoção de um sistema de gangway com compensação de heave, para que o transbordo possa ocorrer de forma mais rápida e confortável. Este sistema, a ser parte integrante do EAV, reduz a capacidade de transporte de pessoas para aproximadamente 200 pessoas.

\section{A SOBERANIA DO PRÉ-SAL}

Em 1718, a Marinha Portuguesa Instalou permanentemente a Divisão Naval do Norte, em Belém, que foi fundamental para a defesa da Amazônia brasileira, pois controlava o seu acesso através do Rio Amazonas. Graças a esta ação, conseguiu-se manter o domínio sobre esta região. Da mesma forma, deve-se proteger o acesso à Amazônia azul, visto que é uma área de extrema importância devido ao petróleo encontrado no pré-sal.

Porém, na ZEE, devido a legislações internacionais, o tráfego marítimo é liberado, dificultando o controle das embarcações que passam nesta área. Logo, qualquer nação pode deslocar seu poder naval em direção às nossas plataformas sem haver nenhum impedimento legal, embora possa haver desavenças políticos.

A defesa das plataformas é um assunto fundamental para a nação, tanto que para salvaguardar a bacia de Campeche, segundo campo petrolífero mais produtivo do mundo e que fornece cerca de dois terços de todo o petróleo bruto do México, a Marinha mexicana estabeleceu um comando próprio para sua defesa.

Os legisladores brasileiros já atentaram para a defesa das águas nacionais e destinaram parte dos royalties do pré-sal para a manutenção da soberania nacional nesta área, entretanto não são investimentos com valores determinados, o que dificulta o planejamento de gastos e investimentos.

O combustível fóssil é a fonte de energia mais utilizada no mundo, e como mais de $90 \%$ do petróleo brasileiro encontra-se no mar, tem-se a necessidade de defender as

\footnotetext{
${ }^{9}$ FONTE: Logistical Challenges for Crew Transportation in Brazilian Pre-Salt Province, Petrobrás, 2011
} 
plataformas extratoras deste combustível, pois para garantir a segurança nacional, deve-se ter pleno controle dos meios de extração, distribuição e processamento do petróleo.

Para tal fim, a Marinha brasileira prepara-se construindo submarinos nucleares, pois estes têm autossuficiência inesgotável e por um longo tempo podem viajar a velocidades altas, mantendo o elemento surpresa. O submarino nuclear só precisa subir para repor alimentos e "desestressar" a tripulação.

O submarino nuclear brasileiro será construído por engenheiros franceses, mas o projeto, de propulsão a diesel, terá sua matriz energética substituída pela energia nuclear, parte onde entram em cena os engenheiros brasileiros. Dominando a tecnologia nuclear, o Brasil entraria para o seleto grupo formado por Rússia, Estados Unidos, França, China e Inglaterra, que são os membros permanentes do conselho de segurança da ONU.

\section{CONSIDERAÇÕES FINAIS}

A descoberta das reservas petrolíferas do pré-sal representam um novo marco na indústria brasileira. A prospecção das reservas do pré-sal não será tarefa fácil, entretanto, a parceria Estado, empresas privadas e comunidade científica certamente resultará boas experiências, ratificando a posição do país como referencia na exploração de petróleo. Esta, que começou pelos campos de Tupi e Jubarte, em maio de 2009 e setembro de 2008, respectivamente, apresenta bons resultados, suficientes para validar a exploração comercial das reservas.

Como resultado da exploração petrolífera, o Brasil passará a ter um importante papel no cenário mundial, exercendo influencia política através das suas condições de mercado. $\mathrm{O}$ Estado passará a atuar de modo a assegurar a soberania nacional sobre as riquezas exploradas, através da Marinha do Brasil, e a regular a exploração das reservas, através da ação conjunta da Petrobras e da Agência Nacional de Petróleo, Gás e Biocombustíveis (ANP).

A atuação das empresas trará também a necessidade de desenvolvimento tecnológico e de mão-de-obra capacitada, gerando uma rápida e profunda transformação na forma como se opera na indústria petrolífera. Esta mudança se aplicará também a sociedade ampla, pois esta se beneficiará do dinheiro advindo do petróleo através dos royalties distribuídos para os municípios, estados e ao país. Desta forma, o desenvolvimento pleno desta indústria, gera desenvolvimento pleno para a nação.

Os desafios logísticos gerados devido às grandes dimensões trabalhadas no pré-sal têm soluções inovadoras, viáveis e de aplicação segura. Portanto, o tamanho do investimento compensa os resultados futuros, mesmo em situações em que o preço do barril esteja muito abaixo do mercado (como projetado). A indústria desenvolveu, com base nos modelos de offshore, uma dinâmica multimodal que alia a velocidade e praticidade do modal aéreo com a capacidade e o menor custo do modal marítimo. $\mathrm{O}$ apoio a plataformas passará a ter uma nova referência, o pré-sal, do mesmo forma que o offshore é visto hoje. Não mais referência somente na exploração riquezas escondidas em águas ultraprofundas, mas também em uma logística de transporte de material, pessoal e carga que será copiada em todas as bacias do mundo.

\section{REFERENCIAS}

[1] ABREU, Guilherme Matos de. Almirante. A Amazônia Azul: O Mar que nos Pertence. 2010

[2] ARAUJO, Ricardo A. The Logistical Challenge of Exploration \& Production in PreSalt Areas. Petrobras. Rio de Janeiro, 2009. 
[3] BALlOU, Ronald H. Gerenciamento da Cadeia de Suprimentos /Logística Empresarial.5 ed. Porto Alegre: Bookman, 2006

[4] BERNSTORFF, Diogo Luís Pereira. Logística de Transporte Marítimo para Exportação: o Braço do Supply Chain Management Global. Estudo de Caso realizado na Weg S.A. Florianópolis, Rio Grande do Sul, 2004

[5] CHRISTOPHER, Martin. Logística e Gerenciamento da cadeia de suprimentos. 2 ed. São Paulo: Pioneira Thompson Lerning, 2007

[6] ESTRElla, Guilherme. Pre-Salt Production Development in Brazil. Petrobras. Disponível em http://www.firstmagazine.com/downloadspecialistpublications.Acesso em fev 2014.

[7] FELIPE, Nelson Fernandes. Dinâmica econômica e recentes transformações no transporte marítimo de cabotagem e longo curso no Brasil: alguns apontamentos sobre a modernização portuária do estado de São Paulo. Presidente Prudente - SP, 2012

[8] FERRO, Fernando; TEIXEIRA, Paulo. Os Desafios do Pré-Sal. Conselho de Altos Estudos e Avaliação Técnológica. Brasília, 2009.

[9] FORMIGI, José Miranda; PINTO, Antônio Carlos Capeleiro; ALMEIDA, Alberto Sampaio. Santos Basin's Pre-Salt Reservoirs Development - The Way Ahead. Offshore Technology Conference. Houston, 2009.

[10] MARTINS, Eliane M. Octaviano; NETTO, Caio César Alvares Loro. Soberania e jurisdição marítima brasileira na zona pré-sal. Disponível em http://portogente.com.br/portopedia. Acesso em mar 2014.

[11] PUCU, Paulo Aliberto Barros. Logística do Escoamento da Produção de Petróleo de Plataformas Offshore via Transporte Naval. Maceió, Alagoas. Fevereiro, 2011.

[12] TORRES, Luiz Carlos; FERREIRA, Hundrsen de Souza. Amazônia Azul: a fronteira brasileira no mar. Revista Passadiço, CAAML, 2005.

[13] TSENG, Yung-yu. The Role of Transportation in Logistics Chain. Adelaide, Austrália, 2005.

[14] VILEMEÁ; E.M.; MOREIRA, M.B.A.; LOUREIRO, R.R. Logistical Challenges for Crew Transportation in Brazilian Pre-Salt Province. Proceedings of th Rina 9th Symposium on High Speed Marine Vehicles. Rio de Janeiro, 2011

[15] Offshore Brazil's pre-salt story: Exploration \& tech investments in 2012, The International Resource, 2012

[16] Petrobrás planeja ilha artificial para apoiar exploração do pré-sal. Jornal O Estado de São Paulo, 2009 